\title{
VOLUNTAD DE PODER E INTERPRETACIÓN COMO SUPUESTOS DE TODO PROCESO ORGÁNICO
}

Will to power and interpretation inside every organic process

\author{
Diego Sánchez Meca \\ UNED
}

RESUMEN: Las lecturas que, entre 1881 y 1883, lleva a cabo Nietzsche de diversos tratados de ciencias naturales, especialmente los de teoría celular de Rudolf Virchow, Wilhelm Roux y Claude Bernard son decisivas para configurar el modo específico y original en el que comprenderá el mundo como voluntad de poder y, en consecuencia, a los organismos vivos y al hombre. En el marco de estas lecturas es, pues, como nace la concepción hermenéutica de la verdad en Nietzsche y el criterio de validación de las interpretaciones, a saber: en qué medida contribuyen a una intensificación del poder, o lo que es lo mismo, en qué medida son capaces de imponerse a otras interpretaciones y vencerlas. En este artículo se desarrolla, pues, la idea de que toda interpretación no es sino un síntoma de crecimiento o de decadencia, por lo que una interpretación que favoreciera el aumento del poder sería más «verdadera» que las que sólo sirven para conservar la vida y hacerla soportable. Tal es el contexto para comprender la afirmación nietzscheana de que el conocimiento no es sino error útil imposible de trascender por «la verdad».

Palabras clave: voluntad de poder - hermenéutica - verdad - interpretación - conocimiento

ABSTRACT: The reading that Nietzsche carried out, between 1881 and 1883, of several treatises on natural science, especially those about cellular theory by Rudolf Virchow, Wilhelm Roux and Claude Bernard, were decisive to shape the specific and original way in which he would understand the world as will to power and, consequently, living organisms and man. It is in the context of these readings that the hermeneutic conception of truth raises in Nietzsche as well as the criterion for validating interpretations, i.e.: in what measure they contribute to the increase of power, or in what measure they can stand out over other interpretations and defeat them. This article develops the idea that every interpretation is a symptom of growth or of decadence; therefore an interpretation that favours the increase of power would be «truer» than those that are only good to conserve life and to make it bearable. Such is the context to understand the statement that knowledge is only useful error, impossible to transcend by «the truth».

Keywords: Will to Power - Hermeneutics - Truth - Interpretation - Knowledge

\section{INSUFICIENCIA DEL DARWINISMO: EL PODER CREADOR DE FORMAS DESDE DENTRO}

Las lecturas que, entre 1881 y 1883 , lleva a cabo Nietzsche de diversos tratados de ciencias naturales, especialmente los de teoría celular de Rudolf Virchow, Wilhelm Roux y Claude Bernard son decisivas para configurar el modo específico y 
original en el que comprenderá el mundo como voluntad de poder y, en consecuencia, a los organismos vivos y al hombre ${ }^{1}$. La teoría celular de estos autores consideraba las células como unidades vitales simples, o sea, como organismos elementales pero sin una autonomía absoluta. Es decir, las células están siempre integradas en un cuerpo, o lo que es lo mismo, en una totalidad jerárquica en la que se insertan y dependen unas de otras. Todo cuerpo viviente es, pues, una organización dinámica que funciona de acuerdo con un principio fundamental de autorregulación interna. Y de esta idea se deriva una forma de comprender la relación entre organismo y ambiente que es distinta a la idea de adaptación defendida por Darwin ${ }^{2}$.

En efecto, en contraposición al adaptacionismo de Darwin, que otorga a las fuerzas selectivas externas el papel determinante, la teoría celular de Virchow y Roux afirmaba la naturaleza endógena del desarrollo del organismo como proceso complejo de interacción. O sea, el organismo es influenciado por lo que le rodea y responde activamente a tales estímulos reorganizándose y reorganizando esos mismos estímulos que le afectan. A su vez, el ambiente es influenciado por esta reorganización del organismo y eso hace que cambie y se transforme. La diferencia entre Darwin y la teoría celular es que, para ésta, tal proceso no se entiende como proceso de adaptación, sino como proceso de autorregulación.

La lucha externa entre los individuos implicada en lo que Darwin entendía como «selección natural» no basta para explicar la emergencia de la diversidad y la adaptación al entorno ${ }^{3}$. Concretamente Roux postulaba una lucha interna entre las partes del organismo para explicar las nuevas funciones adquiridas, que no se pueden derivar de la lucha externa entre los individuos. Nietzsche anota

1. Una marcada influencia tiene en él, como es de sobra conocido, la lectura del libro de W. Roux, Der Kampf der Theile im Organismus. Ein Beitrag zur Vervollständigung der mechanischen Zweckmässigkeitslehre, Leipzig: Engelmann, 1881, que Nietzsche lee el mismo año de su publicación, y que relee de nuevo en 1883. Roux había sido alumno de C. Gegenbaur, E. Haeckel y R. Virchow, y es el fundador de la investigación experimental sobre lo que llamaba «mecánica del desarrollo». Sobre esta influencia véase W. Müller-Lauter, «Der Organismus als innerer Kampf. Der Einfluss von Wilhelm Roux auf Nietzsche»: Nietzsche Studien 7 (1978), 189-235; G. Abel, Nietzsche. Die Dynamik der Willen zur Macht und die ewige Wiederkehr, Berlin: Gruyter, 1998, pp. 113 ss.; A. Mittasch, Nietzsche als Naturphilosoph, Stuttgart: Kröner, 1952, pp. 172 ss.; A. Orsucci, Dalla biologia cellulare alle scienze dello spirito. Aspetti del dibattito sull'individualità nell'Ottocento tedesco, Bolonia: il Mulino, 1992, pp. 192 ss.

2. Nietzsche entra en contacto con el darwinismo sobre todo a través de la obra de F. A. Lange, Geschichte des Materialismus und Kritik seiner Bedeutung in der Gegenwart, Iserlohn: Baedecker, 1877. Han estudiado esta influencia J. Salaquarda, "Nietzsche und Lange»: Nietzsche Studien 7 (1978), 230-260; G. J. Stack, Lange and Nietzsche, Berlin: Gruyter, 1983. Para la discusión sobre la crítica de Nietzsche al darwinismo véase también W. Stegmaier, «Darwin, Darwinismus, Nietzsche. Zum Problem der Evolution»: Nietzsche Studien 16 (1987), 264-287; D. Henke, «Nietzsches Darwinismuskritik aus der Sicht gegenwärtiger Evolutionsforschung»: Nietzsche Studien 13 (1984), 189-210.

3. Nietzsche lo argumenta de este modo: «La utilidad de un órgano no explica su surgimiento, ial contrario!, en la mayor parte del tiempo durante el cual se forma una propiedad, ésta no conserva al individuo y no le es útil, menos que nada en la lucha con las circunstancias exteriores y con los enemigos; ¿qué es, en última instancia, 'útil'? Hay que preguntar ¿útil en referencia a qué? P. ej. lo que es útil para la duración del individuo, podría ser desfavorable para su fortaleza y su esplendor; lo que conserva al individuo podría al mismo tiempo fijarlo y detenerlo en la evolución. Por otra parte, una carencia, una degeneración puede ser de la mayor utilidad en la medida en que actúa como stimulans de otros órganos. Del mismo modo, una situación crítica puede ser condición de existencia al reducir al individuo a la medida en la que se contiene y no se desperdicia» FP IV 7[25]. 
la explicación que daba Roux de la posibilidad del paso de los animales del medio acuático al terrestre $e^{4}$ y subraya que sólo puede producirse por la formación simultánea de millones de propiedades funcionales individuales ${ }^{5}$. Esta simultaneidad sólo se puede explicar por el principio de la autoestructuración funcional y no por el mecanismo darwiniano de la selección natural, que sólo permite pensar en la formación sucesiva de nuevas funciones orgánicas. Que el individuo se modifique para adaptarse al entorno presupone una duración y una conservación que sobrepasa el espacio de su tiempo vital y que, por ello, necesita la hipótesis del funcionamiento de mecanismos hereditarios que transmitan genéticamente las modificaciones adquiridas. Y esto supone admitir implícitamente una concepción teleológica de la naturaleza que Nietzsche rechaza tajantemente ${ }^{6}$. En suma, para Nietzsche «nunca hasta hoy las buenas cualidades de un organismo se han derivado solo de la selección producida por la lucha por la existencia entre individuos» ${ }^{7}$.

En realidad, más que oponerse al darwinismo, las observaciones de Roux pretendían completarlo en la medida en que era evidente que el mecanismo de la selección natural no era capaz de explicar las variaciones en las distintas funciones internas de los individuos. Por ejemplo, no se podía explicar, apelando a él, el desarrollo y las múltiples y complejas diferencias de la circulación sanguínea. No se trata de diferencias producidas por azar y luego seleccionadas en la lucha externa por la existencia. De ahí que Roux postulara la idea de autorregulación y de una diferenciación interna que se realiza a través del proceso de adaptación funcional. Desde esta perspectiva, entonces, el desarrollo de los vasos sanguíneos se produce en virtud del impulso del flujo sanguíneo. Un órgano actúa sobre otro, lo cual, en su trasfondo, lo que tiene lugar en realidad es una lucha entre tales órganos y, en general, entre las partes componentes del organismo en función de gradaciones diversamente diferenciadas ${ }^{8}$. Sí acepta Roux sin reservas, en cambio, la idea de lucha siguiendo la inspiración de Darwin, si bien la aplica para explicar procesos de selección internos ${ }^{9}$. En todo caso, Roux concluye que las intuiciones de filósofos antiguos como Heráclito y Empédocles apuntaban ya a una explicación de las formas estables en la naturaleza como resultado del conflicto entre fuerzas opuestas, intuiciones que hoy habría que reformular a partir de los datos ofrecidos por la investigación empírica y científica.

En efecto, para Roux, la lucha es el elemento esencial de los procesos de formación de las células, los tejidos y los órganos, por lo que se trata de una lucha de un alcance mucho mayor que el que expresaba el propio Darwin con el mecanismo de la selección natural. La lucha entre los tejidos se convierte en

4. Cf. W. Roux, op. cit., pp. 57 ss.

5. FP III 7[9].

6. "Que la 'herencia', como algo completamente inexplicado, no puede ser utilizada para explicar, sino sólo para caracterizar, fijar un problema. Esto mismo vale de la 'facultad de adaptación'. En realidad, con la exposición morfológica, supuesto que fuera completa, no está explicado, sino descrito un enorme estado de cosas. Cómo un órgano puede ser utilizado para cualquier fin, esto no está explicado. Con el supuesto de causae finales se explicaría en estas cosas tan poco como con causae efficientes. El concepto de 'causa' es sólo un medio de expresión, no más; un medio para designar» FP III 36[28].

7. FP III 7[194].

8. W. Roux, op. cit., p. 38.

9. W. Roux, op. cit., pp. 73 ss. 
un principio regulador, un principio de autoestructuración funcional de las relaciones de fuerza más apropiadas ${ }^{10}$. Roux concebía esta lucha desde una óptica mecanicista y distinguía tres modalidades esenciales: la lucha por el espacio, la lucha por el alimento y la lucha directa. En el interior de las células, la partícula que sea capaz de metabolizar más rápidamente que las otras regenerándose más eficazmente ampliará su espacio vital con una fuerza mayor que otra partícula con un nivel menor de asimilación. Es decir, la primera partícula ocupará el espacio de la segunda, y si el proceso se repite la segunda partícula será de nuevo desplazada y así hasta hacerla desaparecer. El mismo proceso tiene lugar si, en vez del espacio, la lucha es por el alimento: las partículas que vencen son las que asimilan mejor y se regeneran más rápidamente. Roux explica, en este sentido, el crecimiento como consecuencia de un superávit de fuerza que resulta de la relación entre asimilación y consumo. Nietzsche resume en estos términos el pensamiento de Roux sobre este punto:

1) lucha de las partes por su espacio y por su alimento, sea o no bajo la influencia de un estímulo; 2) lucha directa con destrucción o asimilación del más débil; 3) los más fuertes son más fecundos que los más débiles; están siempre en ventaja los que, en condiciones de menor afinidad, se regeneran más fácilmente y consumen menos; mejor capacidad de nutrirse y menor consumo para satisfacer las propias necesidades... Cuando falta el alimento los primeros en desaparecer $\mathrm{y}$ en morir de hambre son los que consumen más ${ }^{11}$.

En conclusión, a partir del examen detenido de las teorías de Roux, Nietzsche reconfigura su idea del dinamismo interno de lo orgánico frente al darwinismo. La idea misma de que la formación tiene un origen interno no era nueva para él. Ya en la Segunda consideración intempestiva hablaba de una fuerza plástica en el hombre que construye formas estables frente al flujo y la diversidad del acontecer histórico para poder incorporar el pasado asimilándolo como algo propio. Para mí, dice Nietzsche, «no es lícito que el movimiento esté condicionado desde fuera - no puede estar causado. Necesito inicios y centros de movimiento desde los que la voluntad se propague» ${ }^{12}$. El influjo de las «circunstancias exteriores» ha sido sobrestimado hasta el absurdo por Darwin:

Lo esencial en el proceso vital es precisamente esa enorme fuerza configuradora que crea formas desde el interior y que aprovecha, explota las circunstancias exteriores... (Por tanto) las nuevas formas configuradas desde el interior no son formadas para un fin, sino que en la lucha de las partes una forma nueva no estará mucho tiempo sin una relación a una utilidad parcial y que entonces, de acuerdo con el uso, se conformará de manera cada vez más perfecta ${ }^{13}$.

10. W. Roux, op. cit., pp. 215 ss. «Los tejidos que están demasiado llenos de vida, incluso cuando son más útiles, conducen al todo a su pérdida. Por ejemplo, los tumores son tejidos de este tipo, dotados de una fuerza vital anormal: se desarrollan a expensas del aporte nutritivo y del espacio de otros y destruyen el conjunto. Basta que un tejido se DEBILITE anormalmente para que otro pueda adquirir la preponderancia. Una falta de equilibrio entre los tejidos conduce rápidamente a la muerte de los individuos y a eliminación de éstos y de sus cualidades desfavorables del ámbito de los seres vivos: permanecen solo los estados de equilibrio: así, se cultivaría una unidad armoniosa del organismo entero mediante la autoeliminación de lo que se desvía» FP III 7[190].

11. FP III 7[86]. Cf. también 7[95].

12. FP IV 14[98].

13. FP IV $7[25]$. 


\section{LA LUCHA POR LA LUCHA O CÓMO HACERSE CADA VEZ MÁS FUERTE}

En su aproximación a las investigaciones y teorías científicas relativas a las ciencias de la naturaleza, Nietzsche busca modelos de elucidación y de formalización de sus intuiciones filosóficas. La comprensión del organismo como un complejo de partes que luchan entre sí en función de sus diversas gradaciones de fuerza resultará decisiva en la formulación de su concepto de voluntad de poder como multiplicidad de fuerzas que se contraponen. Para el Nietzsche maduro todos los seres tendrán el carácter de organizaciones configuradas como estructuras de dominación. Y de tal idea se deriva como importantísima consecuencia que la vida no se desarrolla a partir de un simple instinto de autoconservación, como postulaban los evolucionistas darwinianos. La lectura de El organismo como lucha interna, de Roux, le ha convencido de que todo ser vivo tiene continuamente que conquistar su unidad orgánica mediante un proceso de lucha, de asimilación y de autosuperación. El impulso básico de la vida no es conservar una unidad o una identidad estable una vez conseguida, sino nutrirse, crecer y rebasar en cada momento lo ya alcanzado esforzándose en hacerse cada vez más fuerte y ser más, apropiándose de todo aquello que le puede hacer crecer. Por encima, pues, del impulso de autoconservación hay otro más fuerte, poderoso y originario que es la voluntad de todo ser vivo de desarrollar su propia energía y de actualizar todas sus potencialidades. Esta voluntad actúa - o lucha- sobre el medio - o con el medio- para nutrirse y crecer, interpretándolo para asimilarlo o rechazarlo. Nietzsche rechaza claramente la idea de un instinto de autoconservación teleológicamente dirigido a preservar la vida el mayor tiempo posible como instinto humano fundamental ${ }^{14}$.

Entender todo ser como organización estructurada en términos de dominación implica así postular una desigualdad entre sus elementos componentes de la que se suscita una lucha ${ }^{15}$. Allí donde hay vida, hay

una cultura cooperativa en la que los participantes luchan por la alimentación, el espacio, y los más débiles se unen, viven menos y tienen menos descendencia: la diversidad domina en las cosas más pequeñas, espermatozoides, óvulos - la

14. Nietzsche considerará claramente reductivo pensar en la autoconservación como principal, si no el único, objetivo de la lucha por la vida. Sin degeneración (Entartung) de lo que es fijo y estable no existe la posibilidad del progreso, pues el debilitamiento de lo estable es condición para el reforzamiento de lo nuevo. El progreso surge de lo diverso y degenera y convulsiona el orden existente. De ahí que Nietzsche defienda que lo determinante para el progreso no es la lucha por la existencia, sino lo que surge como una excepción del sistema uniforme de la comunidad que sólo quiere autoconservarse. Es el sentido de su famoso fragmento titulado «Anti Darwin» (FP IV 14[23]), en el que imputa a Darwin describir una realidad en la que la vida se orienta a reprimir todo lo que amenaza la propia autoconservación. En tal caso, los peor dotados, o sea, los que sólo viven bien en la uniformidad del rebaño y de la tribu, lo subordinan todo al instinto de autoconservación. En cambio, los que son efectivamente fuertes y mejor dotados son los que actúan individualmente y con independencia de las estructuras impuestas por la comunidad, y por ello son considerados por el rebaño una anomalía o anormalidad que debe inmediatamente ser reintegrada y normalizada o, si no, eliminada. Conclusión: el fuerte, el mejor dotado, las naturalezas ricas y complejas, los que crean cosas nuevas son la excepción, mientras los más débiles, incapaces de vivir sin los esquemas normalizados de lo que da estabilidad y fijeza al sistema social, son los que perduran y se multiplican.

15. FP III 7 [93]. 
igualdad es una gran locura. En la lucha perecen un sinfín de seres, - algunos casos raros se conservan ${ }^{16}$.

Es el modelo que Nietzsche aplica a su comprensión del cuerpo como multiplicidad jerarquizada de seres vivientes que cooperan mediante una lucha con la que mantienen una relativa autonomía ${ }^{17}$. La vida es esencialmente apropiación, asimilación de lo extraño y más débil, reducción de la alteridad (de lo otro o diferente) a lo idéntico o igual (gleich), un hacer-idéntico (Gleich-machen) lo diferente. Mediante este proceso, una relativa autonomía o autosuficiencia parece imponerse lógicamente como el aspecto distintivo de los centros de fuerza del cuerpo. Lo viviente es lo que, gracias a la "autoconstitución de lo necesario para él», se basta a sí mismo ${ }^{18}$. Una asimilación eficaz y sobreabundante determinará, pues, un crecimiento rápido, mientras la persistencia de un centro de fuerza estará garantizada por el principio de autorregulación que mantiene la armonía funcional del conjunto. Y todo ello como resultado de una lucha incesante que parte del interior, si bien se ve también estimulada y condicionada por la influencia del entorno.

Porque, a pesar de la crítica de Nietzsche al principio darwiniano de la selección natural, las influencias externas no se minimizan. Una vez que cada parte dentro de un organismo se ha desarrollado y diferenciado, el crecimiento y, en algunos casos, incluso la sustitución total de lo que se ha llegado a asimilar solo tiene lugar bajo el efecto de un estímulo. Ya Roux hablaba de la excitación como indispensable para el desarrollo de los procesos vitales en cuanto factor, junto con la nutrición, de diferenciación y estructuración: "Se desarrollan procesos - dice Nietzsche- en los que la excitación se hace necesaria, se hace excitación-que-impulsa-a-la-vida (Lebensreiz): a falta de ellos sobreviene la desaparición y el declive. Son los procesos más elevados» ${ }^{19}$. Según Roux, el crecimiento no se produce si el organismo no es activado por lo que él llamaba la «excitación funcional». Por ejemplo, la nutrición —que es, tanto para Roux como para Nietzsche, el mejor paradigma de la «asimilación»— no es más que la respuesta activa de las partes del organismo a una excitación previa. Esta noción de excitación o estímulo (Reiz) era compartida por muchos otros biólogos de la época, y está presente, en concreto, también en Virchow y Claude Bernard, que repite: "Sin excitación no hay trabajo orgánico». En todo caso, no basta con decir que la asimilación (unificación subjetiva) es lo que condiciona la excitación (la diversidad de lo que acontece), sino que hay que comprender que las excitaciones actúan a su vez sobre su condición de posibilidad ${ }^{20}$. En suma, para

16. FP II, parte 2, 11[132].

17. Cf. FP III 7[92]. «La magnífica unión de la vida más variada, la ordenación y disposición de las actividades superiores e inferiores, la obediencia de mil formas, que no es ninguna obediencia ciega, ni menos mecánica, sino seleccionadora, inteligente, respetuosa, incluso que opone resistencia - este entero fenómeno 'cuerpo', medido según la medida intelectual, es tan superior a nuestra conciencia, a nuestro 'espíritu', a nuestro pensar, sentir, querer conscientes, como el álgebra a la tabla de multiplicar» (FP III 37[4]). Este fragmento, del que citamos sólo una pequeña parte, reproduce frases literales del capítulo 1 de la Patología Celular de Rudolf Virchow (Die Cellularpathologie in ihrer Begründung auf physiologische und pathologische Gewebelehre dargestellt, Berlin: Hirschwald, $\left.{ }^{3} 1862\right)$.

18. Cf. JGB $\$ 230$.

19. FP III 7[98].

20. C. Bernard, Leçons sur les phénomènes de la vie communs aux animaux et aux végetaux, Paris: Baillére, 1878. Cf. FP IV 1[128]. 
Nietzsche la dependencia de estímulos externos no sustituye el trabajo interno de la autoestructuración:

A la elección activa, cuantitativa y cualitativa, del alimento de las células que determina todo su desarrollo, corresponde el que el hombre elija también los acontecimientos y los estímulos, o sea, procede activamente ante todo lo que le sucede casualmente - por tanto rechaza muchas cosas ${ }^{21}$.

Éste es el contexto teórico en el que Nietzsche gesta su idea de que todo ser puede quedar reconducido, en último término, a la forma básica de la voluntad de poder, explicándose la diversidad de los fenómenos de la naturaleza, de la vida y del mundo a la luz de ella ${ }^{22}$. El pensamiento, el sentimiento, el querer, así como las funciones orgánicas, la nutrición, la reproducción, serían ramificaciones especializadas de la voluntad de poder en su tendencia constitutiva al logro de su posibilidad máxima. La voluntad más fuerte dirige a la más débil, pues no hay otra causalidad que la de voluntad a voluntad. El pensamiento, como la nutrición, es sólo expresión de la insaciable apropiación de la voluntad de poder. La reproducción, en cambio, expresa la disgregación que sobreviene cuando las fuerzas dominantes resultan desbordadas por la tarea de organizar internamente todo aquello que se han apropiado. En cualquier caso, desde el punto de vista de la voluntad de poder, todo cambio, todo movimiento, se explica como acción de unas fuerzas sobre otras. El mundo es un devenir conjunto de procesos de equilibrios de fuerzas que nuestro cuerpo nos ejemplifica como constelación jerarquizada de sistemas religados a una actividad común. No hay motivos empíricos que nos puedan hacer pensar en regularidades que se mantienen. Al contrario, parecería que un estado logrado debiera conservarse si no hubiese en él un impulso a no quererse conservar. Contra el principio spinozista de la conservación de sí, en cada ser vivo — dice Nietzsche- se puede mostrar del modo más claro que hace todo lo que puede, no para conservarse, sino para llegar a ser más. Decir, en suma, que el mundo es voluntad de poder, es tratar de comprenderlo como un fenómeno de luchas entre centros de fuerza que se jerarquizan en función de sus desigualdades y del dominio de unos sobre otros. Y ello porque su ser consiste, no en conservarse, sino en ejercer su poder sobre otras fuerzas que se le resisten. Por tanto, no conservación de la energía, sino querer ser más fuerte por parte de cualquier centro de fuerza; no preservación de sí mismo, sino voluntad de apropiarse, de adueñarse lo extraño para ser más y poder más. La hipótesis que parte de aquí para abarcar el carácter general de la existencia, la explica como esfuerzo hacia el poder.

21. FP III 7[196].

22. Para la discusión sobre este controvertido concepto en la perspectiva aquí adoptada Cf. W. Müller-Lauter, «Nietzsches Lehre vom Willen zur Macht»: Nietzsche Studien 3 (1974), 1-60; M. Bauer, «Zur Genealogie von Nietzsches Kraftbegriff: Nietzsches Auseinandersetzung mit J. T.Vogt»: Nietzsche Studien 13 (1884), 221-227; B. Babich, «Nietzsche and the Philosophy of Scientific Power: Will to Power as Constructive Interpretation»: International Studies of Philosophy 22 (1990), 78-91; R. Ávila Crespo, Identidad y tragedia. Nietzsche y la fragmentación del sujeto, Barcelona: Crítica, 1999, pp. 190 ss.; M. Barrios, La voluntad de poder como amor, Madrid: Arena Libros, 2007, pp. 113 ss.; D. Sánchez Meca, Nietzsche: La experiencia dionisiaca del mundo, Madrid: Tecnos, ${ }^{3} 2008$, pp. 119 ss. 
Cuando dos seres orgánicos chocan, cuando sólo hay lucha por la vida o la alimentación: ¿cómo? Tiene que haber lucha por la lucha: y dominar es soportar el contrapeso de la fuerza más débil, por tanto, una forma de prosecución de la lucha. Obedecer es asimismo una lucha: cuanta fuerza quede precisamente para resistir ${ }^{23}$.

El instinto de conservación no es el instinto radical: antes bien, «el viviente quiere dejar salir su fuerza, 'quiere' y 'tiene que' (ilas dos palabras valen para mí igual!): la conservación es sólo una consecuencia» ${ }^{24}$. Pero este «tener que» descargar la propia fuerza es una cuestión siempre de poder $^{25}$. Con ella cada ser intenta hacer de sí un ser cada vez más fuerte, lo que no puede lograr sino mediante la lucha que sostiene con lo que se le resiste:

La voluntad de poder sólo puede exteriorizarse ante resistencias; busca lo que se le resiste, - ésta es la tendencia del protoplasma cuando extiende pseudópodos y tantea a su alrededor. La apropiación e incorporación es sobre todo un querer subyugar, un formar, configurar y reconfigurar hasta que finalmente lo sometido ha pasado totalmente al poder del atacante y lo ha acrecentado ${ }^{26}$.

Por tanto, cuando una voluntad de poder se contrapone a otra que se le resiste aspirando a conquistarla e incorporarla, la incorporación y la apropiación se cumplen bajo la forma de una transformación hasta que lo conquistado quede totalmente bajo el poder de la fuerza agresora y lo haga aumentar. Ya en el protoplasma, cuando extiende sus pseudópodos buscando algo que se le resista, su motivo último no es el hambre, sino su voluntad de poder. Lo que hace el protoplasma es el intento de superar lo que se le resiste, de apropiárselo, de incorporárselo. Y lo que se denomina «nutrición» — dice Nietzsche- es meramente un fenómeno ulterior, una aplicación utilitaria de esa voluntad originaria de llegar a ser más fuerte ${ }^{27}$. El hambre no es, pues, el instinto principal, como tampoco lo es la autoconservación. De modo que el hambre, concebida como consecuencia de la infranutrición, significa el hambre como consecuencia de una voluntad de poder que no logra ser dominante.

Por otra parte, esta búsqueda de resistencia para superar el propio poder supone un esfuerzo continuo y, por tanto, un displacer. Nietzsche destaca esta idea del displacer como elemento constitutivo de toda actividad dirigida a vencer resistencias y a situarse por encima de algo que debe ser superado. En la medida en que la voluntad de poder aspira a confrontarse con resistencias como

23. FP III 26[276].

24. FP III 26[277].

25. Hay una influencia directa en Nietzsche, en esta concepción de la descarga de la fuerza como necesidad, del libro de J. R. Mayer, Mechanik der Wärme, Stuttgart: Cotta, 1874, así como de otro estudio del mismo autor publicado dos años después y titulado Über Auslösung. El propio Nietzsche habla de ello en la carta a Peter Gast del 16 de abril de 1881. En ambos escritos, Mayer relaciona todas las manifestaciones del movimiento, tanto en el mundo orgánico como en el inorgánico, con procesos de liberación de fuerzas que no pueden ser medidos o comprendidos de manera matemática. Cf. A. Mittasch, op. cit., pp. 120-127; Cf. también A. Mittasch, Friedrich Nietzsche Naturbeflissenheit, Heidelberg: Springer, 1950.

26. FP IV 9[151].

27. FP IV 14[174]. 
medio necesario para aumentar su propio poder, hay una cierta voluntad de sufrimiento en el fondo de toda vida orgánica que contradice la eudemonista idea de la «felicidad» como «meta» del comportamiento ${ }^{28}$. Se trata, no obstante, de un displacer opuesto al que resulta de una pérdida o disminución del poder, o sea al displacer que es consecuencia de la debilidad y del cansancio que subyacen a la incapacidad de luchar y de resistir. El corolario que de la concepción de la voluntad de poder, como voluntad incesante de más poder, se deriva para la comprensión de nuestras ideas sobre el placer y el displacer no deja, pues, de resultar llamativo. Pues desde esta perspectiva, el ser humano no buscaría el placer ni evitaría el displacer como impulsos o motivos básicos de su conducta, tal como nos enseñan la mayoría de los psicólogos:

Placer y displacer son meras consecuencias, meros fenómenos concomitantes. Lo que el ser humano quiere, lo que quiere cada una de las minúsculas partes de un organismo vivo, es un plus de poder. Al esforzarse por conseguirlo se producen tanto el placer como el displacer; a partir de esa voluntad el organismo busca resistencia, necesita algo que se ponga en contra. El displacer, en cuanto impedimento a su voluntad de poder, es, pues, un faktum normal, el ingrediente normal de todo acontecer orgánico, el ser humano no lo elude, al contrario, lo necesita constantemente: toda victoria, todo sentimiento de placer, todo acontecer presupone una resistencia superada ${ }^{29}$.

El displacer, pues, actuaría en situaciones normales, según este paradigma explicativo, como estímulo del sentimiento de poder. Simplemente no se debe confundir el displacer con esa especie particular de displacer que es el del agotamiento, el cual representa ciertamente una honda disminución y depresión de la voluntad de poder, una sensible pérdida de fuerza, un estado de agotamiento en el que el único placer que todavía se siente es el de dormirse; el placer, en el otro caso, es el de la victoria ${ }^{30}$.

\section{MANDAR Y OBEDECER}

Pero la originalidad de la concepción nietzscheana de la voluntad de poder se muestra, sobre todo, cuando se la confronta con el modo usual en el que la ciencia moderna ha comprendido y tematizado el movimiento, la acción o el acontecer del mundo. Si no hay más causalidad que la que se ejerce de voluntad a voluntad $^{31}$, entonces esta causalidad debe ser de otra clase distinta a esa relación causa-efecto que sirve de clave explicativa fundamental al pensamiento mecanicista. Nietzsche propone un modelo nuevo, el de la relación entre mandar y

28. Cf. FP III 26[275].

29. FP IV 14[174].

30. «La gran confusión de los psicólogos consistía en que no habían distinguido estas dos especies de placer, la del dormirse y la de la victoria. Los agotados quieren tranquilidad, distensión de los miembros, paz, calma - es la felicidad de las religiones y filosofías nihilistas. Los ricos y vivos quieren victoria, adversarios vencidos, desbordamiento del sentimiento de poder sobre ámbitos más vastos que antes. Todas las funciones sanas del organismo tienen esta necesidad - y el organismo entero, hasta la edad de la pubertad, es un tal complejo de sistemas que luchan por el crecimiento de sentimientos de poder» (FP IV 14[174]).

31. FP III 35[15]. 
obedecer, modelo que puede expresarse así de modo conciso: «Un superior, más fuerte, manda y anuncia su sentimiento como ley para los demás» ${ }^{32}$. O también de este otro modo: «Una lucha (Kampf), suponiendo que se entienda esta palabra, tan amplia y profundamente, como para comprender también la relación del que domina con el dominado como un combate (Ringen), y la relación del que obedece con el que domina como una oposición» ${ }^{33}$.

Los supuestos metafísicos en los que se basaba la explicación mecanicista del mundo se han terminado por convertir en pura fábula. El mundo no es más que un conflicto de fuerzas cuyo devenir no procede de ninguna única fuerza que pudiera ser pensada como causa. Las constancias que creemos ver en las leyes naturales no son más que creaciones nuestras. Pues comprender el mundo significa, para nosotros, poder calcularlo, para lo que necesitamos puntos estables de referencia a modo de «leyes naturales». Ahora bien, tales leyes no se encuentran en la realidad, sino que son sólo posiciones de sentido que nosotros hacemos ${ }^{34}$. Lo mismo sucede con los conceptos con los que categorizamos científicamente. El concepto de átomo, por ejemplo, en cuanto componente último de la materia y que nos permite entenderla como estructura constante, no es más que una ficción interpretativa ${ }^{35}$.

En todo acontecer se trata sólo de una lucha entre voluntades de poder que no está regida por ninguna ley, sino dominada sólo por el impulso de cada punto de fuerza a ser más venciendo resistencias. Reducir el devenir del mundo a fórmulas y leyes es sólo el resultado de su utilidad para nosotros. Y si el punto de vista mecanicista es superficial, tampoco la perspectiva teleológica resulta más apropiada. La suposición de causas finales en el acontecer no es más que la intromisión, en la explicación del mundo, de un prejuicio moral ajeno al funcionamiento de la naturaleza:

Al concepto de ser vivo le es inherente que éste tiene que crecer - que extiende su poder y, por consiguiente, que ha de absorber en él fuerzas extrañas. Bajo la obnubilación causada por la narcosis moral, se habla de un derecho del individuo a defenderse: en el mismo sentido sería lícito que también se hablara del derecho que tiene a atacar: pues ambos - y el segundo todavía más que el primero - son necesidades de todo ser vivo - el egoísmo agresivo y el egoísmo defensivo no son un asunto de elección, ni tampoco de la «voluntad libre», sino la fatalidad de la vida misma ${ }^{36}$.

Es decir, la necesidad que parecen expresar las leyes naturales es entendida por Nietzsche como la necesidad con la que tienen lugar las luchas entre voluntades de poder. Pues toda fuerza, por su propia realidad de fuerza determinada,

32. FP III 25[452]; cf. FP III 35[15].

33. FP III 40[56].

34. «Para comprender el mundo tenemos que poder calcularlo; para poder calcularlo tenemos que tener causas constantes; puesto que en la realidad no encontramos esas causas constantes, nos inventamos unas - los átomos. Éste es el origen de la atomística. La calculabilidad del mundo, la expresabilidad en fórmulas de todo acontecer - ¿es esto realmente 'comprender'? ... Después, las 'causas constantes', cosas, substancias, por lo tanto algo 'incondicionado'; inventado - ¿qué se ha alcanzado?» (FP IV 7[56]).

35. Cf. FP IV 14[186] y $14[79]$.

36. FP IV 14[192]. 
sólo se mantiene como tal en virtud de las relaciones de coacción y de resistencia que mantiene con los otros centros de fuerza:

Yo me guardo de hablar de «leyes» químicas: esto tiene un resabio moral. Se trata más bien de una absoluta constatación de las relaciones de poder: lo más fuerte se adueña de lo más débil, en la medida en que éste precisamente no puede imponer su nivel de independencia ${ }^{37}$.

El mundo, pues, es un caos de organizaciones de poder en continuo movimiento de transformación. A su vez, cada ente no es sino una estructura de dominación inserta en una red jerarquizada de quantums o cantidades de poder. En el ser humano, en concreto, "cada impulso es una especie de ansia de dominio, cada uno tiene su perspectiva que quisiera imponer como norma a todos los demás impulsos $»^{38}$. Y en su conjunto los impulsos se asocian unos con otros puntualmente en función de las estrategias de la lucha que les contrapone entre sí, de modo que los resultados de esa lucha producen modificaciones y desplazamientos incesantes de los equilibrios de poder ${ }^{39}$. En el mundo orgánico todo acontecer tiene como trasfondo estas relaciones complejas de fuerzas dispares, de modo que si en él se perciben entidades estables y formas duraderas es porque se interpreta su multiplicidad dinámica como la organización de un juego recíproco y acompasado entre ellas. En el ámbito de lo humano, por ejemplo,

la permanencia, la igualdad consigo mismo, el ser no es inherente ni a lo que se llama sujeto ni a lo que se llama objeto: son complejos del acontecer aparentemente duraderos respecto de otros complejos - p. ej. por una diferencia en el tempo del acontecer, (quietud-movimiento, fijo-cambiante): todas oposiciones que no existen en sí y con las que de hecho sólo se expresan diferencias de grado que se presentan como oposiciones para una determinada medida óptica ${ }^{40}$.

Lo mismo tiene lugar en el mundo inorgánico, de modo que cualquier acontecer no es sino un ritmo, un juego de acciones y reacciones, de aumentos y disminuciones de fuerza en relaciones cambiantes de tensión y enfrentamiento con otras cantidades de fuerza, cuyo ser sólo consiste en esa relación de coacción y de resistencia que toda fuerza, en cuanto tal, mantiene con las demás.

En consecuencia con todo ello, el elemento clave de la concepción nietzscheana de la voluntad de poder es la capacidad de las fuerzas de dominar en el seno de una organización dinámica, dominación que no cabe explicar ni mecanicista ni teleológicamente. Por tanto, no es realmente el superávit de asimilación de poder lo que, en último término, produce el desarrollo de lo orgánico, sino el

37. FP IV 36[18]; «La sucesión invariable de ciertos fenómenos no demuestra una 'ley', sino una relación de poder entre dos o varias fuerzas. Decir: 'pero precisamente esa relación permanece igual a sí misma' no significa más que: 'una y la misma fuerza no puede ser también otra fuerza'. - No se trata de un uno después de otro, sino de un uno en otro, de un proceso en el que los momentos singulares que se siguen no se condicionan como causas y efectos» (FP IV 2[139]).

38. FP IV 7[60].

39. «Las pulsiones provocan que la memoria devuelva sus materiales. - Dicha pulsión desata también la pulsión opuesta, y no sólo esa sino, a la manera de los armónicos, también otras cuya relación no puede caracterizarse con un término tan usual como 'opuestas'» (FP II, parte 2, 6[63]).

40. FP IV 9[91]. 
poder de mandar y de controlar. La voluntad de poder no es ni el ser ni el devenir, sino una acción, o como dice Nietzsche más exactamente, "un pathos, el hecho más elemental sólo a partir del cual resulta un devenir, un producir efectos» ${ }^{41}$. Para explicar el devenir del mundo o el mundo como devenir en términos de lucha entre voluntades de poder es preciso analizar la funcionalidad y las implicaciones del modelo mandar-obedecer, en el que lo primero a destacar es la comprensión del mandar como ese pathos del querer ${ }^{42}$.

Querer significa mandar: pero mandar es un determinado afecto (este afecto es una explosión repentina de fuerza) - tenso, claro, teniendo en cuenta sólo una cosa, íntima convicción de la superioridad, seguridad, de que se obedece. - «libertad de la voluntad» es el «sentimiento de superioridad del que manda» en relación con el que obedece: "yo soy libre», y aquél tiene que obedecer ${ }^{43}$.

El pathos del mando se apoya, pues, en el sentimiento de superioridad de la fuerza que manda respecto de la que obedece. El mandar transmite, pues, algo, pero eso que transmite no es ni la expresión misma de la orden ni su contenido. Mandar, como acción consciente, oculta otra acción inconsciente en la que se esconde el auténtico proceso. Nietzsche señala que el mandato de una voluntad de poder a otra conduce a la modificación consiguiente de ésta. La lucha entre voluntades de poder consiste en ese proceso recíproco: «La única fuerza que hay es de la misma especie que la de la voluntad: un mandar a otros sujetos, que se mudan enseguida ${ }^{44}$. Por tanto, lo que se oculta en la relación mandar-obedecer es la trasmisión de un impulso que se inicia en la voluntad de poder que manda y que tiene como consecuencia que los que obedecen se transformen desde dentro, a partir de ellos mismos, como lo exige la idea de autorregulación que Nietzsche defiende frente al darwinismo. Lo que lleva a cabo el mandar es la activación de esa fuerza de estructuración, de ese poder interior de creación de formas en la voluntad de poder que obedece. De ahí que la voluntad de poder no se exprese sólo en el acto de mandar y de dominar por el que se acumula y se expande la fuerza, sino también a través de lo que es dominado y sometido.

Al comprender la voluntad de poder como un pathos, como el afecto del mando en los términos expuestos, no es entonces correcto hablar de «causas del querer», sino de excitaciones del querer para iniciar su movimiento:

Hay un engaño sobre la voluntad: no es la voluntad la que supera la resistencia - hacemos una síntesis de dos estados simultáneos y ponemos una unidad. La vo-

41. Parece evidente que Nietzsche acuña la expresión «voluntad de poder» con intención de impedir su comprensión «inmediata». Pues utiliza el término «voluntad» cuando argumenta una y otra vez que la voluntad no existe, y que sólo es una palabra vacía. Y utiliza el término "poder» que espontáneamente sugiere el poder político, social, económico, etc. Voluntad de poder, en Nietzsche, no significa, pues, lo que a primera vista parece denotar: aspiración al poder, deseo de dominar, etc. En realidad, voluntad de poder es, para él, el afecto del mando y su ejecución: «Un quantum de poder se define por el efecto que produce y al que resiste» (FP IV 14[79]).

42. «Voluntad - un mandato: pero en la medida en que a este acto consciente subyace uno inconsciente, sólo necesitamos pensar éste también actuando. Pero ċen un mandato a uno que obedece? La palabra del mandato no actúa como palabra, ni como sonido, sino como lo que se esconde por detrás del sonido: y debido a esta acción algo se sigue transmitiendo» (FP III 25 [389]).

43. FP III 25[436].

44. FP III 40[42]. 
luntad como invención (Erdichtung). 1) Se cree que ella misma mueve (mientras que es sólo un estímulo, con cuya llegada comienza un movimiento). 2) Se cree que supera resistencias. 3) Se cree que es libre y soberana, porque su origen nos permanece oculto y porque el afecto del que manda la acompaña. 4) Puesto que en la mayoría de los casos sólo se quiere cuando puede esperarse el resultado, la «necesidad» del resultado es atribuida a la voluntad como fuerza ${ }^{45}$.

La excitación, pues, mueve liberando de este modo su fuerza que impulsa a otra fuerza a aceptar la excitación. Entonces la aceptación de la excitación por parte de otro centro de fuerza se convierte en un contramovimiento autóno$\mathrm{mo}^{46}$. Éste es el marco preciso para entender la idea nietzscheana de jerarquía, que surge de la lucha incesante entre voluntades de poder. La relación entre el que manda y el que obedece establece una jerarquía cuyo modelo último lo encuentra Nietzsche en la interdependencia de los órganos y de los instintos y en la diferencia que de ella resulta entre funciones superiores e inferiores: «Diferencia entre funciones inferiores y superiores: jerarquía de los órganos e instintos, representada por los que mandan y los que obedecen ${ }^{47}$.

\section{EL CARÁCTER INTERPRETATIVO DE TODO ACONTECER}

La voluntad de poder se manifiesta pues, sobre todo, como apropiación, asimilación, incorporación. El crecimiento del poder requiere la asimilación de fuerzas externas mediante la lucha, pues la voluntad de poder no es otra cosa que esta lucha misma cuya consecuencia es el acrecentamiento de fuerza. Esta incorporación de fuerzas extrañas constituye, por ello, un querer superar y transformar, de modo que lo vencido se asimile hasta quedar por completo bajo el poder de la voluntad conquistadora y de este modo haga aumentar su quantum de poder. Tal es el marco conceptual en el que Nietzsche afirma que el proceso orgánico presupone continuamente el interpretar:

La voluntad de poder interpreta: en la formación de un órgano se trata de una interpretación; la voluntad de poder delimita, determina grados, diferencias de poder. Meras diferencias de poder no podrían aún sentirse como tales: tiene que haber allí un algo que quiere crecer que interprete a todo otro algo que quiere crecer respecto de su valor. En verdad la interpretación es ella misma un medio para hacerse señor de algo. (El proceso orgánico presupone un permanente interpretar. ${ }^{48}$

Si la voluntad de poder es voluntad de más poder, la interpretación es la operación concreta de la adquisición del dominio sobre las cosas. En su querer crecer, la voluntad de poder delimita, establece grados, diferencias de poder que

45. FP III 27[24].

46. «En el más pequeño de los organismos se está continuamente produciendo fuerza, de la que luego debe deshacerse: sea por sí mismo, cuando llega al exceso, sea por un estímulo exterior. ¿Hacia dónde se dirige la fuerza? Seguramente hacia lo habitual: esto es, hacia donde le guíen los estímulos, hacia allí se moverá también el desencadenamiento espontáneo. Los estímulos más frecuentes conforman TAMBIÉN la dirección del desencadenamiento espontáneo» (FP II, parte 2, 11[139]).

47. FP III 25[411].

48. FP IV 2[148]. 
se sienten a sí mismas, como tales, en virtud de la confrontación. Es decir, estima las demás voluntades que también quieren poder a partir del sentimiento de su propio valor. Pero, en cuanto ello significa disponer siempre de energía nueva y de mayor fuerza, la voluntad de poder se especializa, básicamente, como voluntad de nutrición, de apropiación, de instrumentalización, desplegando una actividad configuradora. No sólo, pues, la voluntad de poder hace referencia a una lucha dinámica de fuerzas, sino indisociablemente también a la ordenación interna de estas fuerzas por una evaluación-interpretación como incorporación o separación:

La mayor complejidad, la separación tajante, la coexistencia de órganos y funciones desarrollados, con desaparición de los elementos intermedios - si esto es la perfección, resulta en el proceso orgánico una voluntad de poder, en virtud de la cual fuerzas dominantes, configuradoras, ordenadoras aumentan siempre el ámbito de su poder y, en el interior del mismo, lo simplifican continuamente: creciendo el imperativo ${ }^{49}$.

Todo el dinamismo de la realidad física consiste en estos procesos de separación e incorporación bajo el efecto de fuerzas que se ejercen dominándolos y simplificándolos.

El punto de partida de esta argumentación es que, para que una voluntad de poder pueda conquistar e incorporar a otra, primero tiene que poder reconocerla, valorarla, percibir la diferencia de fuerza respecto de ella: «Hay que estudiar la influencia recíproca de lo inorgánico (que es siempre una acción a distancia, por tanto un 'reconocimiento' precede necesariamente a toda influencia: lo que se encuentra a distancia ha de ser percibido) ${ }^{50}$. Las simples diferencias de poder no pueden sentirse a sí mismas de modo aislado, sino que sólo, a partir de su querer ser más, tiene que poder interpretar su valor en confrontación con otro querer que también quiere crecer. Para poder reconocerse a sí misma como poder, la voluntad de poder, en suma, tiene que poder interpretar las diferencias de poder.

Por otra parte, esta percepción consiste en imponer una interpretación a otra voluntad de poder contraria para de este modo conquistarla. Y tal imposición consiste en estabilizar, en fijar una perspectiva de lo que se resiste que, en realidad, es, como fuerza, un devenir cambiante. Todo centro de fuerza, toda voluntad de poder funciona de este modo: fija, estabiliza para dominar, mientras que quien estabiliza y lo estabilizado están sometidos realmente a un devenir constante: «El carácter interpretativo de todo acontecer. No hay ningún acontecimiento en sí. Lo que sucede es un grupo de fenómenos escogidos y reunidos por un ser que interpreta $»^{51}$. Por ello, Nietzsche puede afirmar que el resultado de las percepciones de las voluntades de poder es una relación que organiza los acontecimientos, los cuales no pueden captarse en su devenir, y que tal relación se deshace y se rehace una y otra vez al servicio de la dinámica del proceso de dominación recíproca. De este modo, las voluntades de poder se contraponen, de hecho, como interpretaciones que varían y se transforman según las situaciones. No hay, por tanto, una interpretación como operación llevada a cabo por un

49. FP IV 7[9].

50. FP III 12[27].

51. FP IV 1[115]. 
centro de fuerza a modo de sujeto. Esto es sucumbir a la seducción de la gramática y separar lo que, de manera indisociable, pertenece al hecho de interpretar:

Contra el positivismo, que se queda en el fenómeno «sólo hay hechos», yo diría, no, precisamente no hay hechos, sólo interpretaciones. No podemos constatar ningún factum "en sí»: quizás sea un absurdo querer algo así. "Todo es subjetivo", decís vosotros: pero ya eso es interpretación, el «sujeto» no es algo dado sino algo inventado y añadido, algo puesto por detrás. - ¿Es en última instancia necesario poner aún al intérprete detrás de la interpretación? Ya eso es invención, hipótesis... Son nuestras necesidades las que interpretan el mundo: nuestros impulsos y sus pros y sus contras. Cada impulso es una especie de ansia de dominio, cada uno tiene su perspectiva, que quisiera imponer como norma a todos los demás impulsos ${ }^{52}$.

Es lógicamente en relación a la concepción del conocimiento donde esta idea nietzscheana de la voluntad de poder como interpretación va a ofrecer las perspectivas más revolucionarias. Pues la interpretación, en este contexto, se conecta esencialmente con la facultad propia de todo ser de transformar dentro de sí elementos extraños en algo idéntico. O sea, con la facultad de apropiarse de lo que es cualitativamente extraño para aumentar su fuerza y desarrollarse cada vez más. Sentir es, pues, ya interpretar y pensar. Y este interpretar y pensar básicos conducen a reducir lo diverso a lo idéntico para poder asimilarlo. La asimilación es, en definitiva, lo originario y fundamental del proceso de funcionamiento de la voluntad de poder. O dicho en otras palabras, la nutrición y la digestión, por la que se asimila o se hace propio lo extraño, es el esquema mismo de los procesos de nuestro pensamiento. Es significativo, a este respecto, que para describir la operación que el hombre lleva a cabo cuando, con las categorías lógicas de la razón, cree descubrir el significado mismo del mundo, Nietzsche emplee el verbo zurechtmachen, que significa "acomodar». Porque todas las estructuras con las que el hombre cree conocer el mundo no son sino aquello con lo que él acomoda las situaciones mediante interpretaciones que se construyen y nacen a partir de la necesidad natural de vivir y desarrollar las propias potencialidades vitales ${ }^{53}$.

Puesto que el mundo no es algo estable ni concluido que pueda definirse de una vez por todas, la necesidad de dominarlo es lo que obliga al hombre a producir las estructuras estables (conceptos, palabras, teorías, leyes, etc.) con las que hacer del mundo algo en sí, y entender luego la relación con él como relación sujeto-objeto. Pero ni el objeto ni el sujeto son otra cosa que automovimiento, actividad incesante, un flujo en continuo devenir. Lo significativo es que, una vez

52. FP IV 7[60]; «No se debe preguntar: '¿entonces quién interpreta?', sino que el interpretar mismo, en cuanto una forma de la voluntad de poder, tiene existencia (pero no como un 'ser', sino como un proceso, un devenir) como un afecto» (FP IV 2[151]).

53. «Nuestros valores son introducidos en las cosas con la interpretación. ¿̇Hay entonces un sentido en el en-sí? ¿No es por necesidad el sentido precisamente sentido relacional y perspectiva? Todo sentido es voluntad de poder (todos los sentidos relacionales pueden reducirse a ella). Una $\operatorname{cosa}=$ sus propiedades: pero éstas son iguales a todo lo que nos concierne en esa cosa: una unidad bajo la cual resumimos las relaciones que para nosotros entran en consideración. En el fondo, las alteraciones percibidas en nosotros (- exceptuadas aquellas que nosotros no percibimos, p. ej. su electricidad). In summa: el objeto es la suma de los impedimentos experimentados que se nos han vuelto conscientes. Por consiguiente, una propiedad expresa siempre algo 'útil' o 'perjudicial' para nosotros». FP IV 2[77]. 
impuesta una determinada estabilidad al mundo reconstruyéndolo como texto, el ser humano olvida el carácter que esa interpretación tiene de pura construcción ficticia, útil, instrumental, y se autoconvence de que ese texto escrito por él es, en realidad, el mundo en sí, su verdad que se impone a nosotros. De ahí la convicción de los filósofos que creen haber encontrado en las «categorías de la razón» la forma de acceder a una verdad y a un saber absolutos y objetivos. Pero dominando y controlando el acontecer mediante el manejo de esta organización estable fetichizada como faktum, se crea una escisión, una separación insalvable entre hombre y mundo. El hombre se forja la ilusión de ser, no sólo algo diferente, sino, sobre todo, algo superior al mundo. En realidad, esto no es más que una fantasía infantil compensatoria, fruto de la debilidad, que se genera para apaciguar el miedo. Porque al convencerse ilusoriamente de que la naturaleza y el mundo pueden ser controlados y dominados, el ser humano deja de sentir el miedo y la humillación que le produce la constatación de que el mundo no es sino un flujo continuo en devenir incontrolable, movimiento imprevisible de múltiples elementos sobre los que él no tiene poder alguno:

La forma se considera como algo duradero y por lo tanto más valioso; pero la forma es simplemente inventada por nosotros; y aunque con frecuencia «se alcance la misma forma», esto no significa que sea la misma forma... La forma, la especie, la ley, la idea, el fin - aquí se comete en todos los casos el mismo error de introducir una falsa realidad por debajo de una ficción: como si el acontecer llevara en sí algún tipo de obediencia... Esta coacción de formar conceptos, especies, formas, fines, leyes — «un mundo de casos idénticos»— no debe comprenderse como si con ello estuviéramos en condiciones de fijar el mundo verdadero; sino como coacción de arreglarnos un mundo en el que nuestra existencia sea posible - con ello creamos un mundo que es para nosotros calculable, simplificado, comprensible, etc... El mundo se nos aparece lógico porque previamente nosotros mismo lo hemos logificado ${ }^{54}$.

En el origen, pues, del concepto usual del conocimiento filosófico y científico estaría el miedo a lo desconocido. Conocer se entiende, entonces, como imposición al devenir de las estructuras y esquemas de la razón para reconducir lo desconocido a lo conocido y familiar. La verdad no es adecuación entre conocimiento y cosa, sino una operación útil al desarrollo de la vida. Lo cual no hace de Nietzsche realmente ni un pragmatista ni un utilitarista, puesto que, para él, esa verdad útil no es sino una ilusión, un error útil con el que fijamos el devenir para hacer posible nuestra existencia. No hay nada que pueda ser considerado propiamente un "conocimiento objetivo». Porque el centro de fuerza que conoce no puede hacerlo «neutralmente», o sea, sin la participación esencial de sus instintos, sentimientos, necesidades, prejuicios, etc., en todo lo cual consiste. No hay ningún sujeto separado y distante frente a un mundo estable como objeto exterior a él. El hombre es parte del mundo y actúa siempre, se lo proponga o no, desde el interior de esta pertenencia. Lo que la ciencia hace no es explicarnos el mundo descubriendo sus leyes de funcionamiento interno. Esas leyes las han construido los científicos, y la ciencia lo que hace es proponer una ordenación, un texto desde el cual poder interpretar lo que nos afecta y nos sucede.

54. FP IV 9[14]. 
Junto con los modelos de inteligibilidad extraídos de las ciencias naturales y de la fisiología para hacer comprensibles sus intuiciones filosóficas, Nietzsche utiliza también el modelo de la relación filológica texto-interpretación para poner de manifiesto aspectos fundamentales de la existencia. A partir de este modelo, aplicándolo de maneras diversas, Nietzsche va ofreciendo pistas sobre todas las cuestiones que se derivan, en relación a la cuestión del conocimiento, de su concepción básica de la voluntad de poder. En concreto, desde el carácter perspectivista de toda voluntad de poder y su percepción de lo que se le opone de maneras múltiples, Nietzsche desarrolla el argumento de la diversidad de interpretaciones ${ }^{55}$ frente a la afirmación clásica de una verdad como interpretación única o saber absoluto:

No se vuelve a encontrar en las cosas nada que uno mismo no haya introducido en ellas: ¿este juego de niños, al que no quiero menospreciar, se llama ciencia? Al contrario: icontinuemos con ambos, para ambos hace falta mucho valor - unos para volver a encontrar, los otros - nosotros - para introducir ${ }^{56}$.

Aportar, pues, y reencontrar son los dos aspectos centrales del hecho de interpretar. El aportar es el momento de la creación, de la innovación, mientras el reencontrar es prestar atención a lo antes aportado y redescubrirlo.

En este contexto, el único criterio válido para juzgar sobre la «verdad» de las interpretaciones es en qué medida contribuyen a una intensificación del poder, o dicho también de este otro modo: en qué medida son capaces de imponerse a otras interpretaciones y vencerlas. Toda interpretación no es, en este sentido, sino un síntoma de crecimiento o decadencia: "Infinita interpretabilidad del mundo: cada interpretación, un síntoma de crecimiento o de decadencia ${ }^{57}$. Una interpretación que favoreciera el aumento del poder sería más «verdadera» que las que sólo sirven para conservar la vida y hacerla soportable ${ }^{58}$. El conocimiento no es sino error útil, imposible de trascender por «la verdad». Por tanto, ni siquiera la consideración misma del conocimiento como error universal puede tener el carácter de un saber absoluto. De hecho, el descubrimiento, a lo largo de la historia del pensamiento, de los múltiples errores y contradicciones del conocimiento — que ha hecho posible, finalmente, la consideración generalizada de todo conocimiento como error útil-, no puede tener nada que ver, en el planteamiento de Nietzsche, con la idea de un progresivo acercamiento a una verdad absoluta, aunque sea negativa. La pérdida de una ilusión - dice- no engendra una verdad, sino solamente un ensanchamiento de nuestro vacío, un engrandecimiento de nuestro desierto. Este recorrido no es, por tanto, más que

55. «El mismo texto permite innumerables interpretaciones: no hay una interpretación 'correcta’» (FP IV 1[120]).

56. FP IV 2[174]; «Interpretación, no explicación. No hay ningún hecho, todo es fluido, inaprensible, fugaz; lo más duradero son aún nuestras opiniones. Introducir un sentido - en la mayoría de los casos una nueva interpretación por encima de una vieja interpretación que se ha vuelto incomprensible y que ahora es sólo un signo» (FP IV 2[82]).

57. FP IV 2[117].

58. «Las interpretaciones hasta ahora tenían todas un cierto sentido para la vida — conservándola, haciéndola soportable, alienándola, refinándola, incluso separando lo enfermo y conduciéndolo a la muerte; mi nueva interpretación proporciona a los filósofos futuros como señores de la tierra la necesaria imparcialidad» (FP III 40[12]). 
el trabajo de superación de la vida por mediación de voluntades diferentes. Lo cual se comprende si se tiene en cuenta que la voluntad de poder no es esencialmente búsqueda de la utilidad para la autoconservación, sino esfuerzo de autosuperación también en la forma del combate intelectual. De ahí que Nietzsche pregunte si, en el desarrollo del espíritu, lo que anda en juego es, no la cuestión de la salvación del hombre en su encuentro último con «la verdad», sino la elevación del cuerpo a una forma superior de vitalidad. Con estas palabras resume él sus posiciones en relación con este tema:

Que el valor del mundo reside en nuestra interpretación (- que quizá en alguna parte sean posible otras interpretaciones, diferentes de las meramente humanas -), que las interpretaciones habidas hasta ahora son estimaciones perspectivistas en virtud de las cuales nos mantenemos en vida, es decir, en la voluntad de poder, de crecimiento del poder, que toda elevación del hombre lleva consigo la superación de interpretaciones más estrechas, que toda fortificación y ampliación de poder que se alcance abre nuevas perspectivas y hace creer en nuevos horizontes - esto recorre mis escritos. El mundo que en algo nos concierne es falso, es decir, no es un hecho, sino una invención y un redondeo a partir de una magra suma de observaciones; está siempre «fluyendo», como algo que deviene, como una falsedad que continuamente vuelve a trasladarse, que no se acerca nunca a la verdad: porque — no hay «verdad ${ }^{59}$.

59. FP IV 2[108]. 